www.jmscr.igmpublication.org Impact Factor 5.84

Index Copernicus Value: 83.27

ISSN (e)-2347-176x ISSN (p) 2455-0450

crossref DOI: _https://dx.doi.org/10.18535/jmscr/v5i5.17

Journal Of Medical Science And Clinical Research

\title{
Perinatal Outcome in Twin Pregnancy
}

Authors

\section{Dr R. Simi, Dr P.Lekshmi Ammal}

\begin{abstract}
Background: Multiple pregnancy poses definite risks not only to the mother, but also to the fetuses. Despite improvement in obstetric and neonatal care, risk to the new born remains at least 3 times more than that of singletons. The main contributor to the increased incidence of perinatal mortality and morbidity in twins is prematurity. It is therefore not surprising that the increase in neonatal death in twins is proportionately greater than fetal death. Other problems are fetal mal presentations and the complication of shared fetal circulation in monizygotic twins.

Objectives: To determine the perinatal mortality of twin pregnancies

Materials and Methods: This is a descriptive study conducted in SUT Medical college Vattappara and SRMC Medical college for a period of one year. 200 cases of twin pregnancies beyond 28 weeks of gestation admitted during this period was included in the study group. Pregnancies with more than 2 fetuses were excluded from the study. The perinatal outcome of the babies were analyzed based on the gestational age, birth weight, Apgar scores at birth, NICU admission, still births, intrauterine deaths and neonatal deaths.

Results: Perinatal mortality in twin pregnancy in the present series is $11 \%$ and this was 3 to 4 times higher than that of singleton pregnancy.

Conclusion: Despite advances in Obstetrics and Gynaecology, the perinatal mortality of twins still remains high, three to four times higher than that of singleton. There is clearly a direct relationship between the morbidity and mortality of multiple gestations and the significantly high rate of preterm deliveries, as well as increased incidence of small for gestational age babies associated with these pregnancies.

Keywords: Twin pregnancy, Perinatal mortality, Prematurity.
\end{abstract}

\section{Introduction}

Twin pregnancies are a unique but common obstetrical occurrence that has attracted the attention of both the obstetrician and the common man since time immemorial. The number and rate of twin triplet and other higher order multiple births have increased in the United States at an unprecedented pace over the past two decades (Kogan and colleagues, 200; Martin and Park 1999). Advances in assisted reproduction and an increasing proportion of older mothers have contributed to a increase of $40 \%$ in twin pregnancies. This extraordinary increase in multiple births is a public health concern because these infants are less likely to survive and more likely to suffer lifelong disability due to preterm delivery. Multiple gestations currently accounts for 3\% of all pregnancies (ACOG, 1998). Twins account for $94 \%$ of all multiple births each year. Communications on twins are abundant and reflect the multidisciplinary approach followed in the study of this biologic phenomenon. Therefore it is not surprising that serious efforts have been made to unify all kinds of contributions on twins into a new branch of science named germellology. 
Multiple pregnancy poses definite risks not only to the mother but also to the fetuses. Complications may occur during antenatal, intrapartum and postpartum period. The complications are an increased incidence of hyperemesis gravidarum, gestational hypertension, polyhydramnios, preterm labour, abnormal presentations, uterine inertia and postpartum uterine atony. Despite advances in obstetrics and neonatology the perinatal mortality rate among twins still remains high, estimated as accounting for approximately $10 \%$ of all perinatal mortality. The higher preterm delivery rate in twins, either from spontaneous or induced labour, with its associated problems of prematurity remains the major cause of morbidity and mortality. Other factors which contribute to the higher perinatal mortality include fetal growth retardation, birth weight discordance, fetal anomalies and problems specific to monochorionic twin gestations like twin to twin transfusion syndrome. In addition to the traditional indicators of perinatal morbidity and mortality, twin pregnancies are associated with a number of financial, personal and social costs for their families. Because of the increase in preterm birth, there is also an increase in the incidence of cerebral palsy in twins compared to singletons. The financial costs related to the care of low birth weight children continue long after neonatal intensive care. This study endeavors to evaluate the etiological patterns of twin pregnancies and the increased risks to the mother and twin fetuses and hopes to suggest remedial measures to improve the fetomaternal outcome.

\section{Materials and Methods}

Study Design: Descriptive

Setting: Department of Obstetrics and Gynaecology, SUTl, Medical College, Thiruvananthapuram and SRMC Medical college Varkala.

\section{Methods of Data Collection}

This study was conducted during the period from May 2016 to April 2017. 200 cases of twin pregnancies beyond 28 weeks of gestation admitted during this period were taken as the study group. Pregnancies with more than 2 fetuses were excluded from the study.

200 cases of twin pregnancies more than 28 weeks were followed from the antenatal period upon their admission to the antenatal ward and the labour room. Detailed history was taken. Age of the patient, parity and history of having taken any ovulation induction drugs were noted. Family history of twinning was asked. History of any antenatal complications in all the three trimesters were noted. The number of cases of IUGR and discordancy detected prenatally by ultrasound were recorded. Chorionicity by ultrasound was also taken into consideration. The mode of onset of labour whether spontaneous or induced and mode of delivery whether abdominal or vaginal were evaluated. Presentation of fetuses were noted at the time of delivery.

The usual investigations were done in all cases and special investigation (like PIH profile, FBS, PPBS, Doppler ultrasound) etc were done whenever necessary. Antenatal corticosteroids were given routinely in all cases presenting with preterm labour and in complicated cases needing early termination. Induction was required in some cases for various obstetrical indications. Detailed clinical examination, local examination and per vaginal examination was done.

In labour, patients were watched for progress. Once the first twin was delivered, per abdominal examination and a per vaginal examination was repeated and delivery of the second twin was facilitated. Blood was arranged in almost all cases and active management of third stage of labour was practiced.

Chorionicity of placenta was noted after delivery of both the babies. Time interval between the delivery of the twins was noted. Apgar scores of babies were noted at 1' and 5'. The patients were discharged on the $3^{\text {rd }}$ day after vaginal delivery. Only those who had undergone caesarean section or whose babies were in the NICU (Neonatal Intensive Care Unit) stayed back. The perinatal outcome of the babies was analysed based on the gestational age, birth weight, Apgar scores at birth, NICU admission and factors like number of 
macerated births, still births, NND's etc. Outcome of $1^{\text {st }}$ and $2^{\text {nd }}$ twin were compared. Perinatal mortality with respect to chorionicity was calculated. The relationship of IUGR and discordancy with respect to chorionicity was also evaluated.

\section{Statistics}

Statistical analysis was performed using Chi square test and the significance was assumed at $\mathrm{p}$ value of $<0.05$.

\section{Results}

Twins constituted $1.9 \%$ (208 cases) of total number of deliveries during the study period. $43 \%$ of twins (86 cases) were in mothers of the age group $20-24$ years. $49.5 \%$ cases were primigravida. History of ovulation induction was there in 31 cases $(15.5 \%)$. Out of which 30 were induced with clomiphene citrate and one with gonadotropins.

Table 1 - Maternal Complications in twins

\begin{tabular}{|l|c|c|}
\hline Maternal complications & Number & Percentage \\
\hline Threatened abortion & 7 & 3.5 \\
\hline Hyperemesis & 25 & 12.5 \\
\hline Gestational hypertension & 50 & 25 \\
\hline Mild preeclampsia & 22 & 11 \\
\hline Severe preeclampsia & 25 & 12.5 \\
\hline Eclampsia & 1 & 0.5 \\
\hline Hellp & 2 & 1 \\
\hline Anemia & 43 & 21.5 \\
\hline Gestational diabetes mellitus & 16 & 8 \\
\hline Hydramnios & 9 & 4.5 \\
\hline Abruption placentae & 6 & 3 \\
\hline Placenta previa & 6 & 3 \\
\hline Preterm labour & 36 & 18 \\
\hline Prom & 63 & 31.5 \\
\hline PPH - Mild & 21 & 10.5 \\
\hline PPH - Severe & 13 & 6.5 \\
\hline
\end{tabular}

There was PROM in 63 cases $(31.5 \%) .30$ cases $(47.6 \%)$ had onset of PROM between $35-37$ weeks. Preterm labour was detected in 36 cases $(18 \%)$.

Discordance was present in $10 \%$ cases by ultrasound and IUGR was identified in $9 \%$ cases. $55 \%$ were found to have dichorionic placenta by ultrasound.
Table 2 : Gestational age at the onset of labour

\begin{tabular}{|l|c|c|}
\hline GA & Number & Percentage \\
\hline $28-31 \mathrm{wks}$ & 8 & 4 \\
\hline $32-34 \mathrm{wks}$ & 26 & 13 \\
\hline $35-37 \mathrm{wks}$ & 110 & 55 \\
\hline $38-40 \mathrm{wks}$ & 56 & 28 \\
\hline Total & 200 & 100 \\
\hline
\end{tabular}

$55 \%$ had gestational age between $35-37$ weeks at the onset of labour. Most common presentation was vertex - vertex, amounting to $48 \%$ of the cases. $63.5 \%$ had normal vaginal delivery. $36.5 \%$ required caesarean section. 4 cases needed caesarian for the second of twin.

Table 3 Analysis according to birth weight of babies

\begin{tabular}{|c|c|c|c|c|}
\hline \multirow{2}{*}{$\begin{array}{l}\text { Birth weight in } \\
\mathrm{Kg}\end{array}$} & \multicolumn{2}{|c|}{$1^{\text {st }}$ twin } & \multicolumn{2}{|c|}{$2^{\text {nd }}$ twin } \\
\hline & No & $\%$ & No & $\%$ \\
\hline$<1 \mathrm{~kg}$ & 6 & 3.02 & 6 & 3.02 \\
\hline $1-1.4 \mathrm{~kg}$ & 12 & 6.03 & 21 & 10.5 \\
\hline $1.5-1.9 \mathrm{~kg}$ & 56 & 28.14 & 56 & 28.14 \\
\hline $2-2.4 \mathrm{~kg}$ & 78 & 39.00 & 80 & 40.00 \\
\hline $2.5-2.9 \mathrm{~kg}$ & 40 & 20.1 & 29 & 14.5 \\
\hline $3-3.4 \mathrm{~kg}$ & 8 & 4.02 & 7 & 3.5 \\
\hline $3.5-3.9 \mathrm{~kg}$ & 0 & 0 & 1 & 0.5 \\
\hline Total & 200 & & 200 & \\
\hline
\end{tabular}

The mean birth weight of first twin was $2.09 \mathrm{~kg}$ and the second twin was $2.03 \mathrm{~kg}$.

Table 4 Congenital anomalies in twins

\begin{tabular}{|l|c|}
\hline Type of congenital anomaly & Number \\
\hline Congenital heart disease & 3 \\
\hline Ambiguous genitalia & 1 \\
\hline Cleft lip and cleft palate & 2 \\
\hline Hypospadiasis and micropenis & 2 \\
\hline Hydrops foetalis & 2 \\
\hline Bilateral CTEV & 1 \\
\hline Total & 11 \\
\hline
\end{tabular}

NICU admission was required in $28.5 \%$ of second twin and $23 \%$ of first twin. Most common indication of NICU admission was prematurity followed by IUGR, low birth weight and birth asphyxia. 
Table 5 Indication of NICU admission

\begin{tabular}{|l|c|}
\hline Indication & Number \\
\hline Prematurity & 35 \\
\hline Hypoglycemia & 10 \\
\hline Preterm with HMD & 10 \\
\hline Birth asphyxia & 15 \\
\hline Meconium aspiration & 5 \\
\hline Sepsis & 9 \\
\hline Severe IUGR, LBW & 15 \\
\hline Hyperbilirubinemia & 4 \\
\hline
\end{tabular}

Out of the 400 babies in the study 375 (93.5\%) were live births, $21(5.5 \%)$ were Macerated births and 4 cases $(1 \%)$ were still births.

Table 6 Perinatal mortality rate

\begin{tabular}{|l|c|c|c|c|c|}
\hline $\begin{array}{c}\text { No of } \\
\text { babies }\end{array}$ & $\begin{array}{c}\text { Macerated } \\
\text { birth }\end{array}$ & $\begin{array}{c}\text { Still } \\
\text { birth }\end{array}$ & $\begin{array}{c}\text { Neonatal } \\
\text { death }\end{array}$ & $\begin{array}{c}\text { Total } \\
\text { PND }\end{array}$ & $\begin{array}{c}\text { PMR / 1000 } \\
\text { BIRTH }\end{array}$ \\
\hline 400 & 21 & 4 & 31 & 56 & $110 / 1000$ \\
\hline
\end{tabular}

Table 7: perinatal outcomes according to birth order of twins

\begin{tabular}{|l|c|c|c|c|}
\hline \multirow{2}{*}{ Outcome } & \multicolumn{2}{|c|}{$1^{\text {st }}$ twin } & \multicolumn{2}{c|}{$2^{\text {nd }}$ twin } \\
\cline { 2 - 5 } & Number & $\%$ & Number & $\%$ \\
\hline Macerated birth & 10 & 5 & 11 & 5.5 \\
\hline Fresh still birth & 2 & 1 & 2 & 1 \\
\hline NND & 12 & 6 & 19 & 9.5 \\
\hline Admission to NICU & 46 & 23 & 57 & 28.5 \\
\hline
\end{tabular}

Perinatal mortality of $2^{\text {nd }}$ twin was $130 / 1000$ births, compared to $90 / 1000$ for the $1^{\text {st }}$ twin. ( $p<$ $0.025)$.

\section{Discussion}

In our series, twins constituted $1.9 \%$ of the deliveries. $43 \%$ cases belonged to $20-24$ years age group. This compares well with a retrospective analysis of 188 twin pregnancies by Anahita et $\mathrm{al}^{[1]}$. $49.5 \%$ cases were primigravidas. The positive effects of increasing maternal age and parity were well demonstrated by water house. The reason for the reduction in the incidence of pregnancies in grand multi may be due to implementation of effective family planning methods. Increased incidence in primigravida may be because they account for the largest percentage in the study population and $15 \%$ conceived after treatment for infertility. $15 \%$ (31cases) gave history of ovulation induction. Mahmut et al in his retrospective analysis of 261 cases of twin pregnancies also gave history of ovulation induction in $10.25 \%{ }^{[2]}$.
$25 \%$ cases in the present series had gestational hypertension. $12.5 \%$ had severe pre Eclampsia. A large prospective trial by Sibai et al also confirmed a significantly increased risk (12.9\%) for gestational hypertension and $12.7 \%$ for pre Eclampsia in twins compared to singleton ${ }^{[3]}$.

The most important complication in twin pregnancy leading to increased perinatal mortality and morbidity is preterm labour. Preterm labour complicated $10 \%$ of cases. Majority had onset between 35 - 36 weeks and $40 \%$ between $31-$ 34 weeks. The general incidence varies in different studies between $20-75 \%$. Mahmut et al reported the incidence of preterm labour as $23 \%$ and PROM as $8.8 \%{ }^{[2]}$. Preterm birth is the main reason for the poor perinatal outcome in twins. Incidence of preterm delivery in the present study was $45 \%$. Houtton $M$ reported the incidence of preterm birth as $50 \%{ }^{[4]}$. Yin Bin Cheung et al suggested that optimal gestational age to twins to be between 37 - 39 weeks; this is associated with minimum neonatal and infant mortality and morbidity ${ }^{[5]}$.

The average birth weight of $1^{\text {st }}$ twin was $2.09 \mathrm{~kg}$ and the $2^{\text {nd }}$ twin was $2.03 \mathrm{~kg}$. This may be explained by the increased incidence of IUSR and prematurity in twin. Anahita Pandole also reported the average weight of $1^{\text {st }}$ twin as $2 \mathrm{~kg}$ and $2^{\text {nd }}$ twin as $1.7 \mathrm{~kg}$. ${ }^{[1]}$.

The incidence of congenital malformation in our study was $2.6 \%$. mahmut et al reported congenital anomalies in $3.6 \%$ cases ${ }^{[2]}$.

NICU admission were more for $2^{\text {nd }}$ twin $(28.5 \%)$ compared to $23 \%$ for $1^{\text {st }}$ twin. Most common cause of NICU admission was prematurity, low birth weight, IUSR and birth asphyxia. In our series there were 56 perinatal deaths in 400 fetuses. 31 cases were neonatal deaths. Important cause of NND were prematurity with respiratory distress and hyaline membrane disease. Anahita et al reported 64 perinatal death in 376 fetuses ${ }^{[1]}$. The perinatal mortality in our series was $11 \%$. High perinatal mortality of $17.02 \%, 11.5 \%$ and $17.4 \%$ were reported by Anahita et al, Chabra et al and Rani et al respectively in various studies conducted in our country ${ }^{[1,6,7]}$. 
Perinatal mortality of $2^{\text {nd }}$ twin was $143 / 1000$ compared to $99.7 / 1000$ for $1^{\text {st }}$ twin. This is comparable to report by Anthony Armson et al ${ }^{[8]}$. This excess risk was evident independent of presentation, chorionicity or sex of the infant, but was associated with vaginal delivery, birth weight discordance and prolonged inter delivery interval.

\section{Conclusion}

Despite advances in Obstetrics and Gynaecology, the perinatal mortality in twins still remain high, 3 -4 times higher than that of singletons. There is clearly a direct relationship between the morbidity and mortality of multiple gestations and the significantly high rate of preterm deliveries, as well as increased incidence of small for gestational age babies associated with these pregnancies.

Furthermore there is an increased risk of maternal complications such as gestational hypertension, anemia, antepartum hemorrhage, postpartum hemorrhage, PROM, preterm labour in twins.

\section{References}

1. Anahita Pandole, M S C Swamy, Nagendra Sardesh Pande, Anjali Mishra, shailesh J Kore, V R Ambiye. J Obstet Gynecol Ind. 2003:53[2]; 138 - 139.

2. Mahmut Erdemoolu, Kale A, Akdeniz N, Yalynkaya A, Ozcan Y, Yayla M. Perinatal journal 2005; 13[4]: 213 - 217

3. Sibai B, Hauth J, Caritis S, Hypertensive disorders in twin versus singleton. Am J obstet Gynecol. 2000; 182: 938 - 942.

4. Houlton M, Marivate M, Philpott R. The prediction and fetal growth retardation in twin pregnancy. Bjog. 1981;88:264 - 273.

5. Yin Bun Cheung, Paul Yip. Mortality of twins and singletons by gestational age. American journal of Epidemiology; Vol.152 No12: 1107 - 1116.

6. Chabra S, Bhandari V, Aber I. Perinatal outcome in twin pregnancy. Part $2-\mathrm{J}$ Obstet Gynecol Ind. 1994; 44: 552 - 8.

7. Rani R, Kharoon S, Arrora R. Perinatal outcome in twin pregnancy, a retrospective study. J Obstet Gynecol Ind. 1995; 45:723 -31 .

8. Anthony Armson, Collen O' Connell, Persad V, Joseph K S. Determinants of perinatal mortality and serious neonatal morbidity in the second twin: Obstetric \& Gynaecology 2006; 108: 556 - 564. 